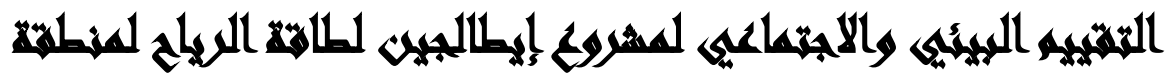

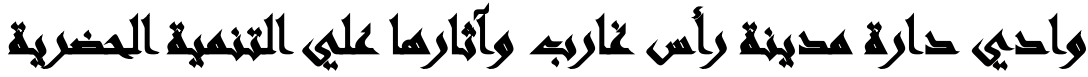

[9]

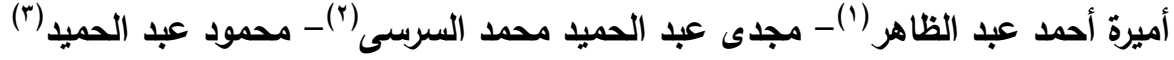

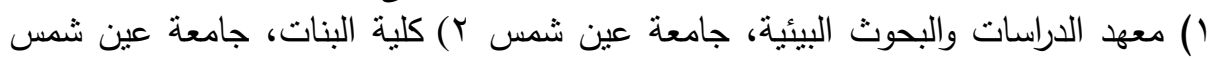
r) كلية الآداب، جامعة دمباط

\section{المستحلv}

استهدفت هذه الدراسة بصفة أساسية عرض متطلبات التثييم الييئي والاجتماعي لمشروع طاقة

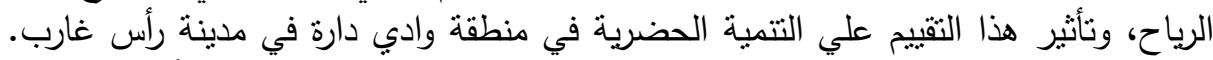

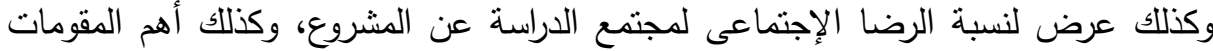

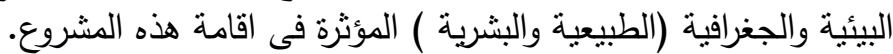

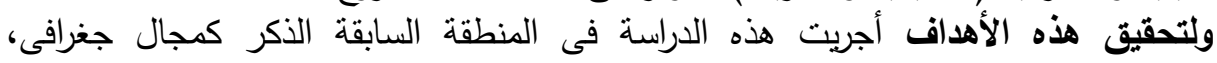

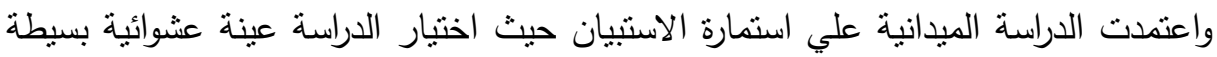

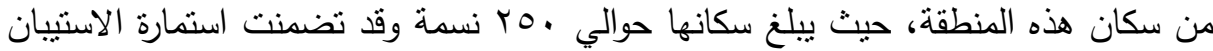

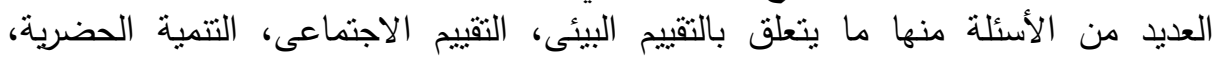

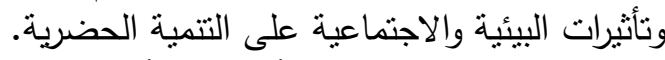

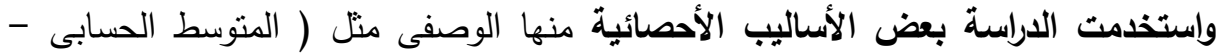

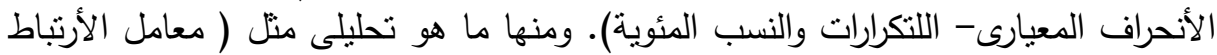

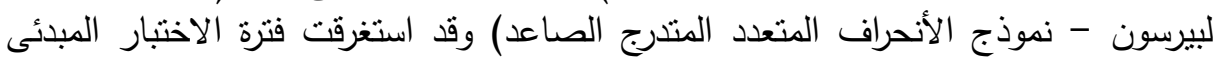

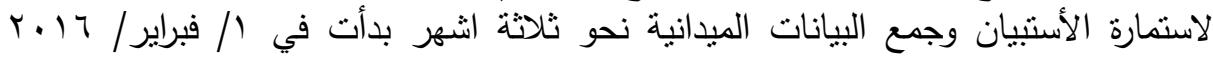
قد انتهت الدراسة إلي أهم نتائج وما أفرزته هذه النتائج من توصيات علمية قابلة للنطبيق بما

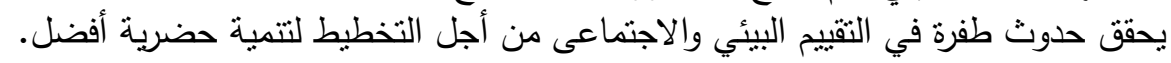

\section{Xanantl}

برزت علي الساحة العالمية والاقليمية والمحلية قضية استخدام الطاقة الجديدة والمتجددة

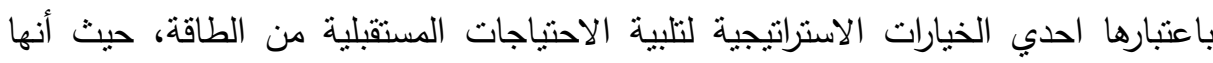
طاقة لا نتضب بسبب استمرار تجددها مادام الكون مستمر ، كما أنها طاقة مأمونة المصدر

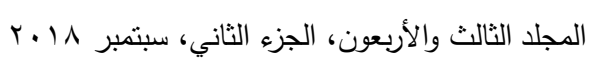


لايمكن احتكارها ولا السيطرة عليها مثل كالوقود الاحفرورى، بالإضافة إلي إنها طاقة نظيفة

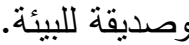

وهناك ارتباط شديد الصلة بين نجاح التتمية وما ينم توفيرة من الطاقة بإعتبارها المحرك الرئيسى لها وهو ما اضاف بعدا شديد الاهمية. ( تقرير الجهاز المركزي للتعبئة العامة

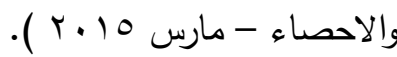
جاء في القمة العالمية لطاقة المستقبل التي تعقد بمركز أبو ظبي للمعارض أن الوقت

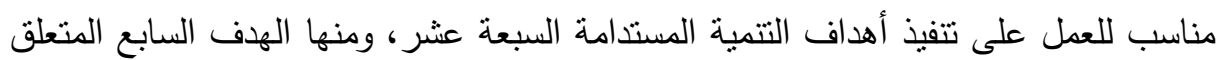
بضمان الحصول على الطاقة بأسعار معقولة بشكل موثوق به ومستدام للجميع ". (www.un.org الغرض من تقييم الأثار البيئية هو ضمان حماية البيئة والموارد الطبيعية والحفاظ عليها - بما فى ذلك الجوانب المرتبطة بصحة البشر - من آثار التتمية التى تفتقد السيطرة عليها والهدف بعيد المدى لهذا التقييم هو ضمان تتمية اقتصادية متواصلة تلبى حاجات الوقت الحاضر دون الانتقاص من قدرة الأجيال القادمة على تلبية حاجاتها الخاصة، ويعد تقييم

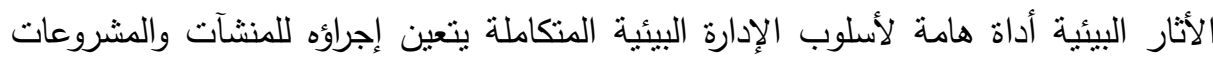

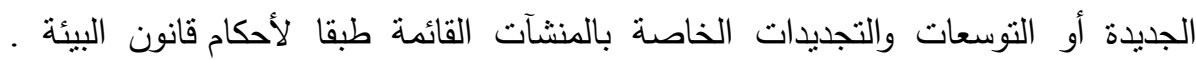
(www.eeaa.gov.eg يعتبر خليج السويس( الثواطئ الثمالية الغربية للبحر الأحمر ) موقعاً رئيسياً من الطراز العالمي لتوليد الطاقة من الرياح على الثاطئ بسبب السرعة والثبات المواتيين لنظم الرياح. تبلغ مساحة الأرض التي منحتها هيئة الطاقة الجديدة والمتجددة NREA إلى شركة اليطالجين حوالي Y Y,Y,Y كم كتقريباً، مقسمة إلى مرحلنتين حيث تبلغ مساحة المرحلة الأولى حوالي

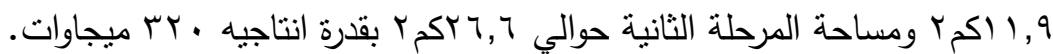

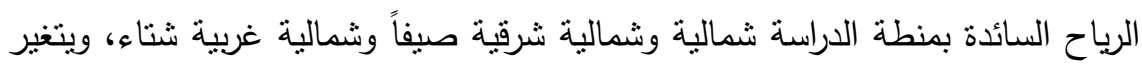
إنجاة الرياح وسرعتها في اليوم الواحد (Refaat\& Aref,2001,p,46)، ونادراً ما تكون لهنه (الرياح جنوبية أو جنوبية شرقية، ويحدث ذللك أثناء العواصف الموسمية المسماة الأزيب ) ( Frihy et al., 1996, P.325) 
أهم أسباب اختيار منطقة الدراسة انها أقرب منطقة سكنية حيث تبعد عن المشروع جنوباً

بحوالي ككم ويسكنها مجموعة من البدو منتميين إلي قبائل العبايدة والبشايرة والمعايزة.

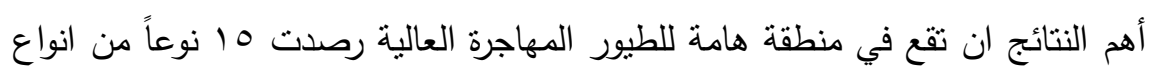

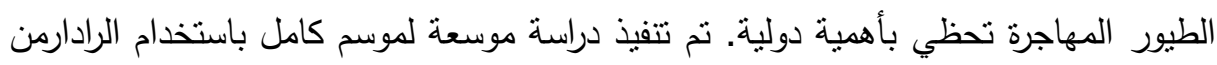

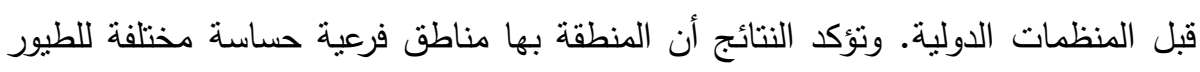

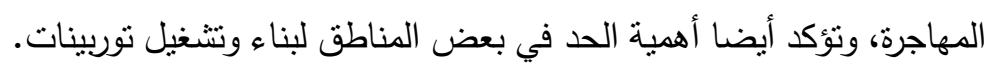

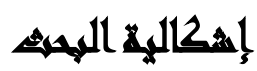

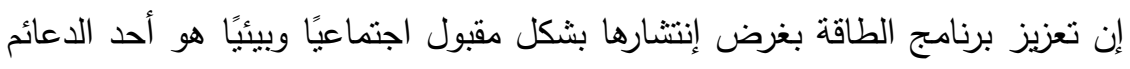

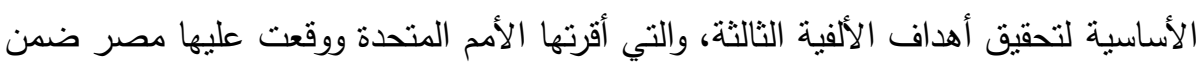

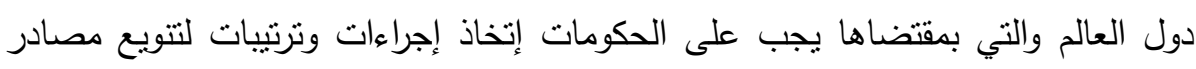

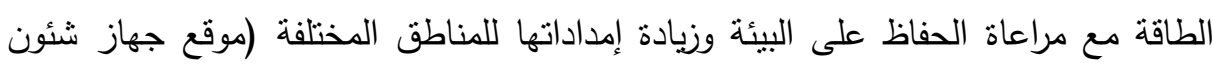
www.eeaa.gov.eg( البيئة

رغم الجهود التي تبذلها الدوله في توفير البيانات الازمة للثركات والدكاتب التي تقوم

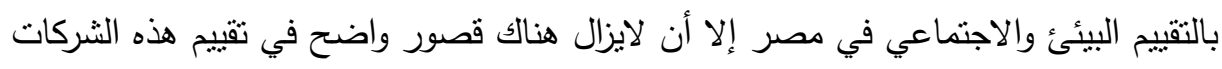

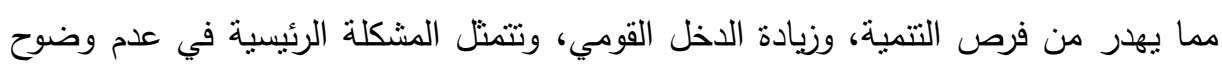

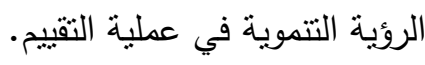

\section{أسرئلة المهيه}

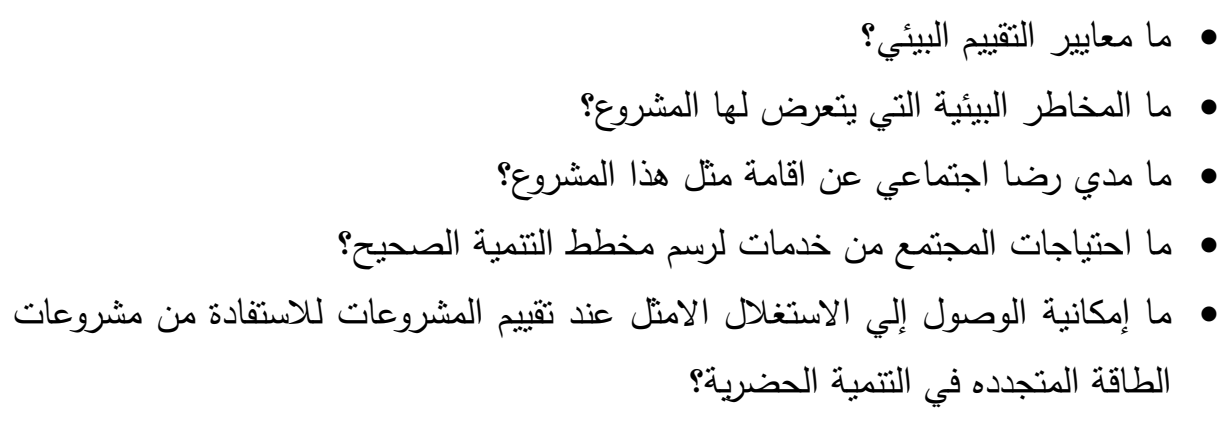

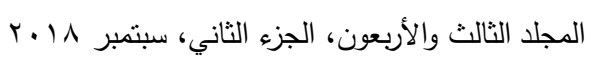




\section{أهمية الهبهي}

علي المستوي العلمي: تمثل الدراسة محاولة للمساهمة في الجدل العلمي للإقتييم البيئي

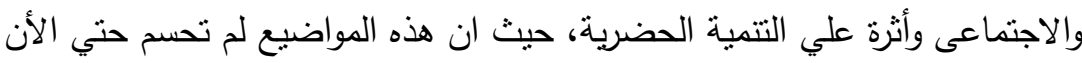

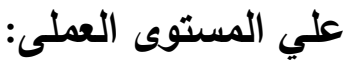

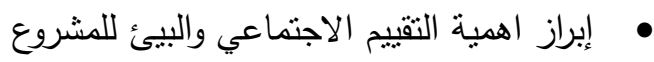

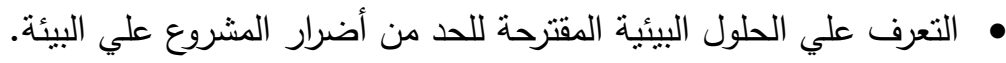
• • الوقوف علي أهم احتياجات مجتمع الدراسة من خدمات تتموية .

أهما اهت المهيد

تتمثل أهداف الاراسة فى هدف رئيسى وتتفرع منه عددة أهداف فرعية كما يلى:

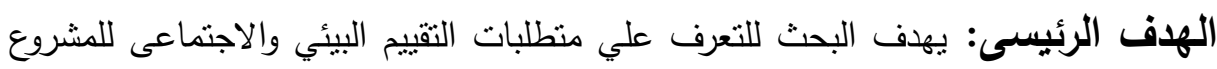

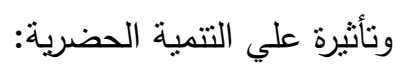

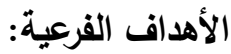
• • التعرف على المنطلبات الطبيعية والبثرية للنقييم. • • التعرف على الاثار السلبية للمشروع علي البيئة. • • التعرف علي احتياجات القرية من خدمات. • • التعرف على الحلول لاهم المشكلات البيئية التي نواجة المشروع.

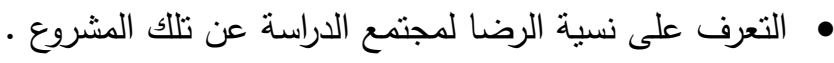
• • إختبار العلاقة بين التقييم والتتمية الحضرية. 


\section{السراسايش السابرهي}

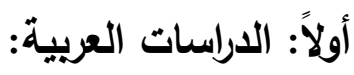

1-دراسة مقبل محمد على(11 + (Y): رسالة ماجستير عن الإشعاع الثمسي والرياح ودورها فى إنتاج الطاقة فى الجمهورية اليمنية دراسة فى الجغرافيا الاقتصادية - والتي نتاولت:

دراسة الطاقة المتجددة من منظور جغرافي كونه فرع من فروع الجغرافيا الاقتصادية.

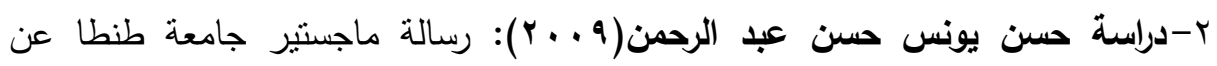
الإثعاع الثمسي والرياح كمصادر للطاقة الجديدة فى مصر - دراسة في المناخ النطبيقي رياح والتى تتاولت عدد محدود من محطات الرصد فى مصر وتتاولت دراسة مفصلة لتلكي

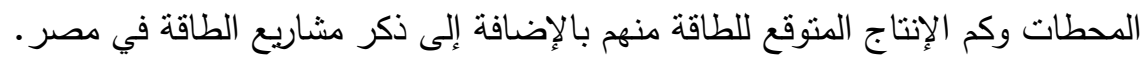

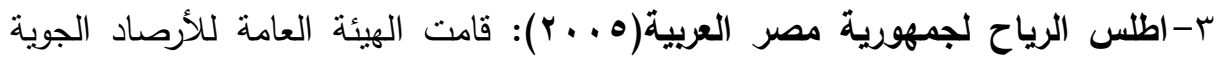
بالاشتراك مع هيئة الطاقة الجديدة والمتجددة ومؤسسة ريزو الدنمركية بتوقيع برونوكول لتنفيذ مشروع أطلس الرياح لجمهورية مصر العربية وذلك منذ أكتوبر 991 ام، التي كانت بعض نتائجة كالأتي:

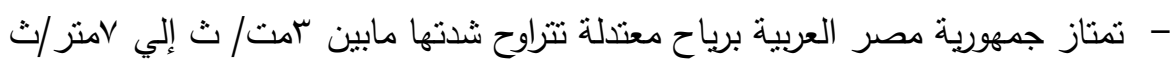
- أعلي سرعة للرياح تحدث بطول سواحل البحر الأحمر، جنوب ووسط سيناء، مصر العليا (حول أسوان ) شمال مدينة بورسعيد، وفى منطقة العوينات.

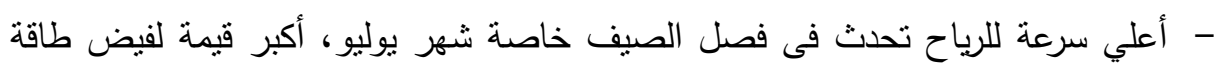

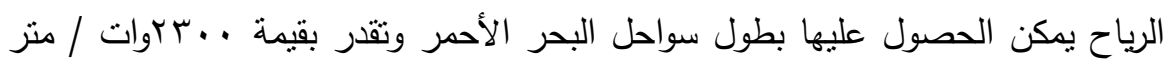
مربع.

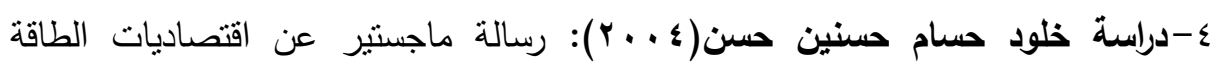
الجديدة والمتجددة وإمكانيات استثمارها فى مصر كلية التجارة جامعة عينة عين شمس قدم الاقتصاد، وتتاولت: دراسة جميع أنواع الطاقات المتجددة وكيفية توليد الكهرباء وتحلية الماء منهم مع ذكر لبعض مشاريع الطاقة الثمسية في مصر . 
ه-دراسة المنظمة العربية للثقافة والعلوم( · . . ب): سلسلة أبحاث في مجال الطاقة المتجددة التي نشرت في نونس والتي تتاولت: أبحاث حول الطاقة الثمسية الحرارية والخلايا الثمسية الفوتوفولتية وطاقة الرياح وتربينات الرياح وتحديث عن خزن ونت الطاقة المتجددة وإقتصاديات الطاقة الجديدة والمتجددة.

$$
\text { ثانياً: الدراسات الأجنبية: }
$$

1- Peter Walsh, Sian Wilson, Laura Martinez, (2010), Report about Severn Tidal Power (Air and Climatic Factors), UK

تقرير يحتوى قواعد الاستفادة من الطاقة المتجددة في الاقليم الأوبي وفى المملكة المتحدة والتركيز الأكبر على طاقة الرياح من خلال دراسة مسبقة لجودة الرياح التي تنكن

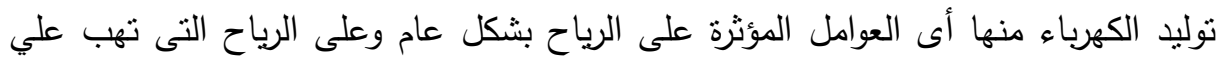

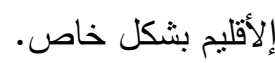

2- Hazem Ahmed Emad Mahroos, Ehab Hussain Mohamed, (2010) Graduation project (Generation OF Electricity By Win Power), Alexandria Higher Institute For Engineering And Technology.

تتاول هذا البحث المنشور والمنبادل بين الجامعات الأخرى توليد الكهرباء بواسطة الطاقة

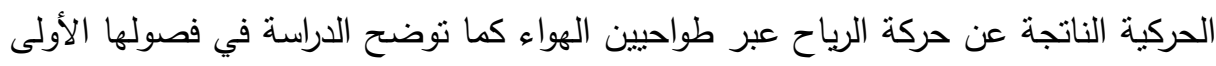
التعريف بالطاقة المتجددة وإلقاء الضوء الأكبر على طاقة الرياح وسبل استغلالها.

3- Financing For Renewable Energy in The Mediterranean Region Project,United Nations Environment Program, International Energy, Agency, Baseline Survey of The Renewable Energy Sector Egypt,(2003).

إصدار من وكالة الطاقة العالمية عن مشروع اقتصاديات الطاقة المتتجدة فى إقليم

البحر المتوسط وتتاولت بيانات عن محطات الرصد فى هذا الأقليم وكم الطاقة المتوقع منها والمشروع قيد التطبيق. 


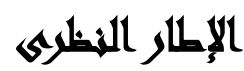

استعرض الباحثون فى دراستهم أساليب التقييم البيئي والاجتماعى التي يجب مراعاتها

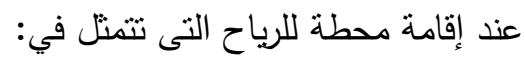

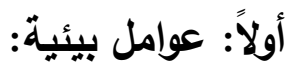

• مظاهر السطح: حيث يجب أن يكون الموضع الذى تقام فيه مزرعة الرياح مكشوفأ ولا

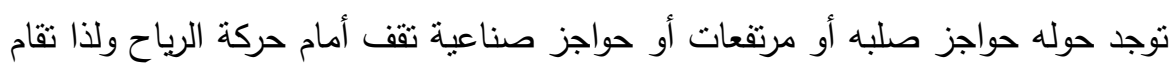

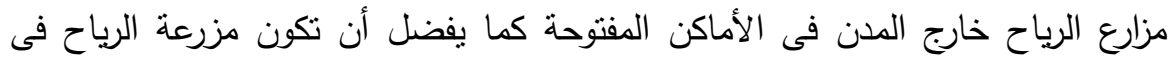

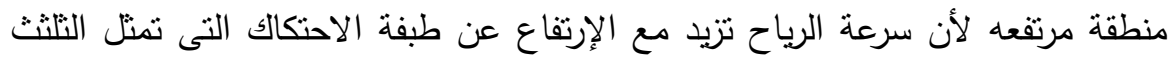

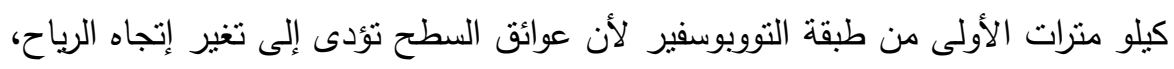
إذ ينقسم التبار الواحد إلى عدة أقسام وفقأ للتضاريس.

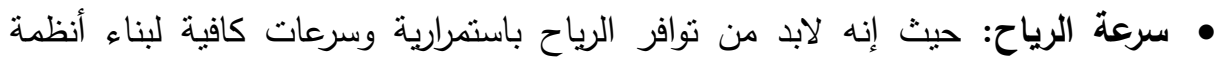

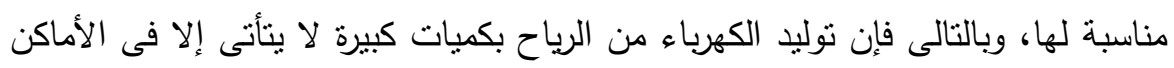

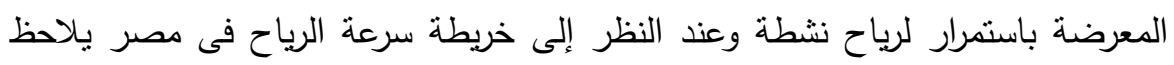

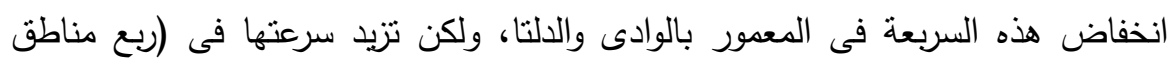

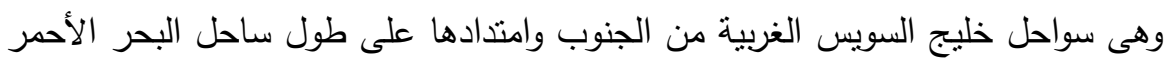

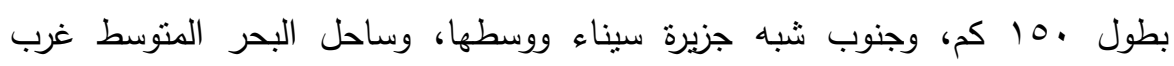
الإسكندرية وشرق العوينات.

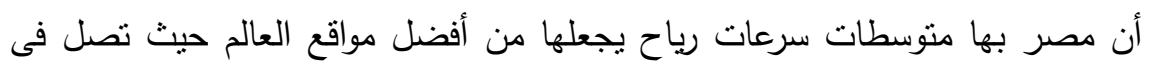

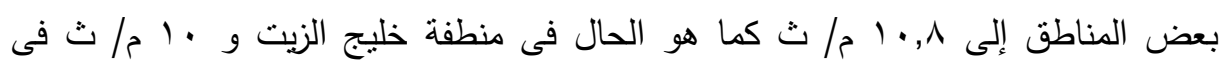

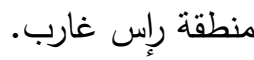
ثانياً: دور طاقة الرياح في الحفاظ علي البيئة: إن إنبعاث غاز ثاني أكسيد الكربون الناتج عن استخدام الطاقات المتجددة والتقليدية في توليد الكهرباء لا ينتج عنها انبعاث ثاني أكسيد الكربون أثناء تتغيل المحطة في حين أنها تتتج إنبعاث في حالة التثييد ويكاد يكون 
منعدم بالمقارنة بالطاقة الثقليدية والتي تتتج إنبعاثات كبيرة مما يثبت أن الطاقة المتجددة

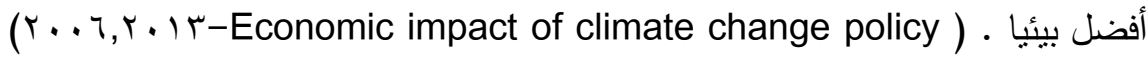
هذا فضلا عن أن طاقة الرياح والتي تعتبر بديل للطاقة التقليدية في إنتاج أهم وأكبر

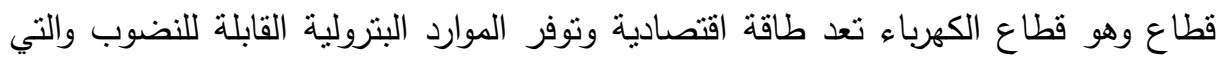

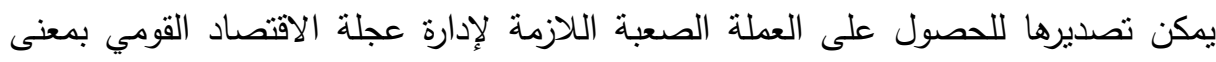

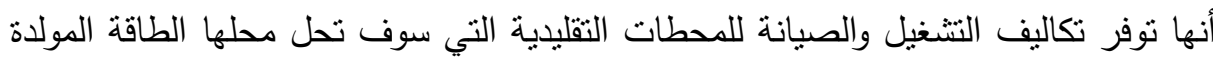
من طاقة الرياح حالة توافرها غير أنها توفر الغازات الحابسة للحرارة والملوثة للبيئة ثالثاً: الآثار الأيجابيه علي البيئة: إن إستخدام طاقة الرياح في نوليد الكهرباء يقلل من تئن تلوث البينة وذلك مقارنة بالوقود الحفري ( فحم - بترول - غاز طبيعي) حيث إن إستخدام الوقود الحفري والفحم والزيت والغاز الطبيعي لتوليد الكهرباء يؤدي إلى تلوث الماء والهواء

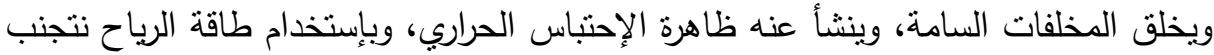

$$
\text { كل هذه الثأثيرات والأخطار . }
$$

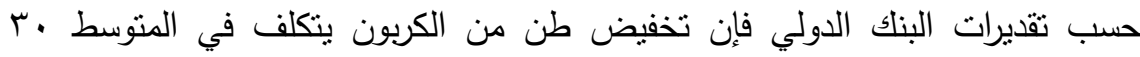

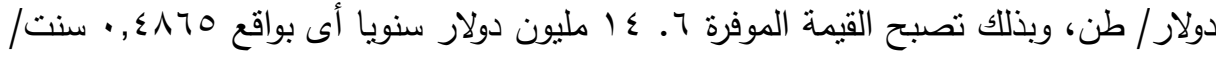

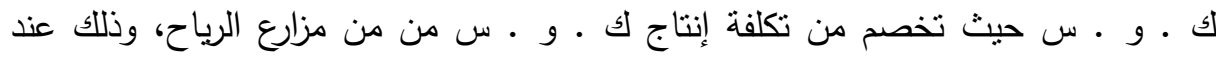

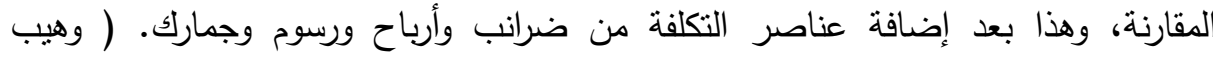

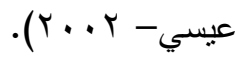

ا-اثر طاقة الرياح علي الهواء: تلوث الهواء الناتج من الوقود الحفري وإستخدامه في توليد

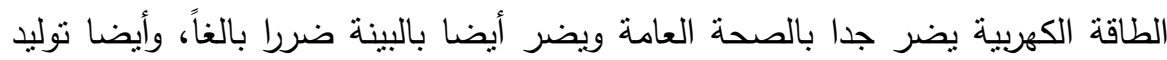

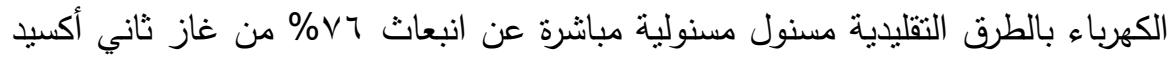

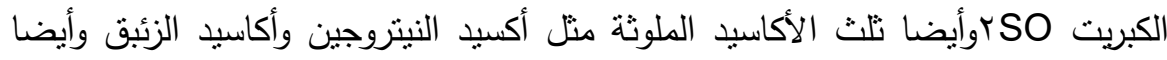

$$
\text { نصف كمية ثاني أكسيد الكربون الملوث للغلاف الجوي. }
$$

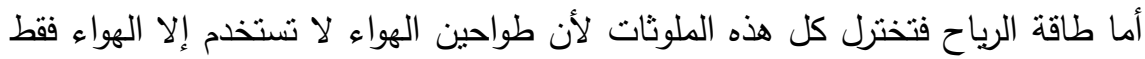
لتوليد الكهرباء عن طريق طواحين الهواء دون استخدام أى وقود حفري.

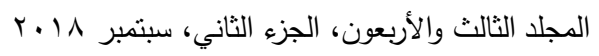


أليس هذا مشجعا على إستخدام هذا النوع من الطاقة النظيفة وأن يتخذ زعماء العالم

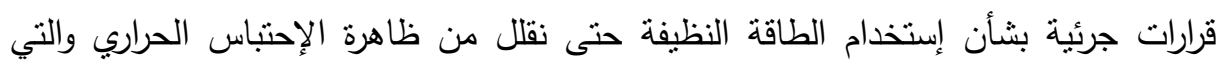

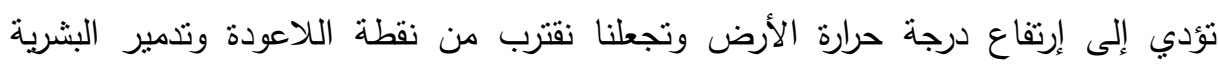
بالكامل. ( رئاسة الجمهور يةٌ - 2003 ) ).

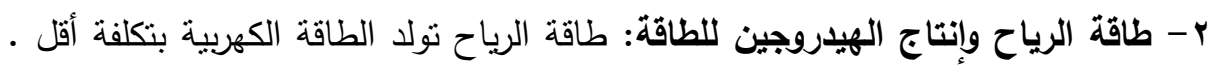

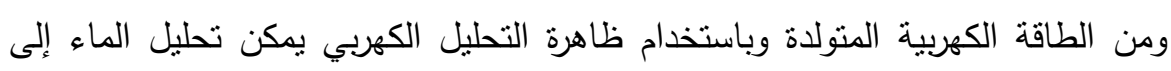

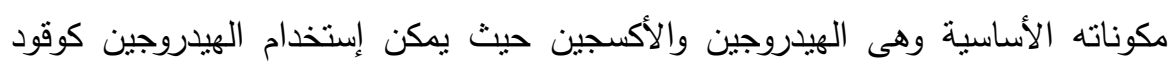

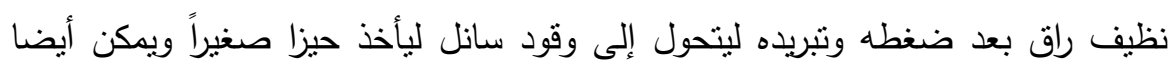

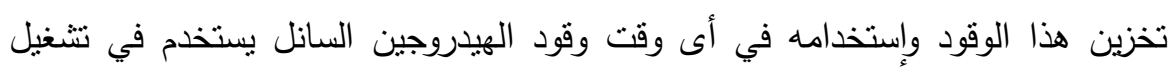

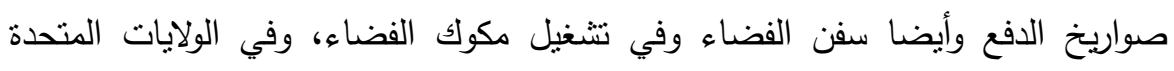

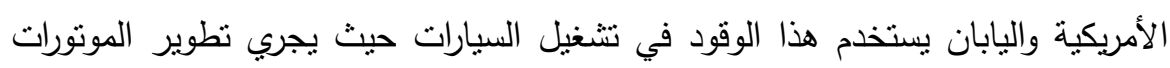

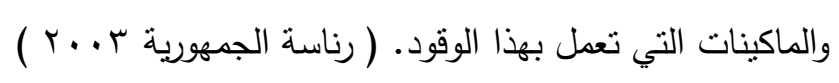

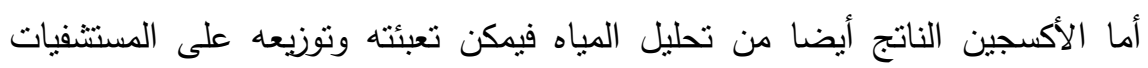

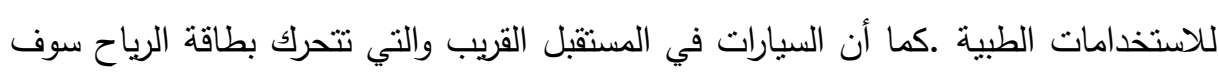

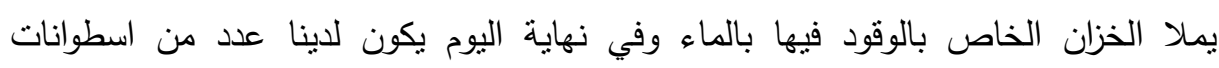

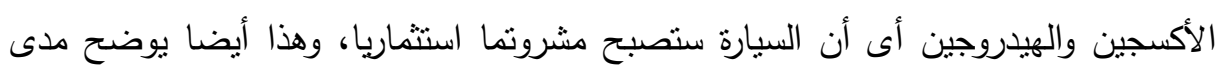

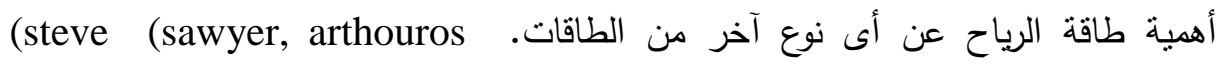

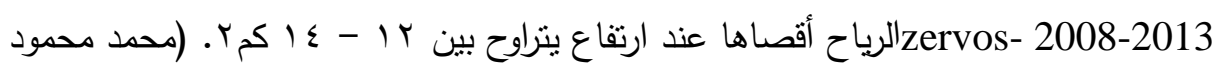

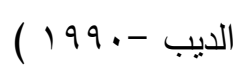

رابعاً: الاثار السلبية لطاقة الرياح: من الدعروف أن طاقة الرياح من الطاقات النظيفة

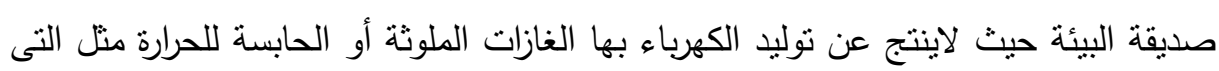

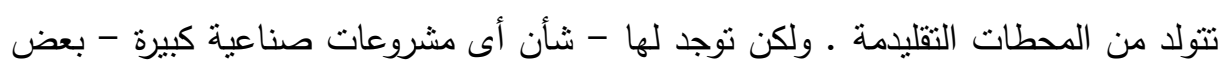

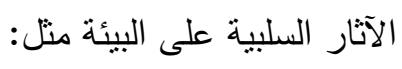


1 - أثرها على هجرات الطيور: من المحتمل نتيجة استخدام طاقة الرياح قتل بعض الطيور

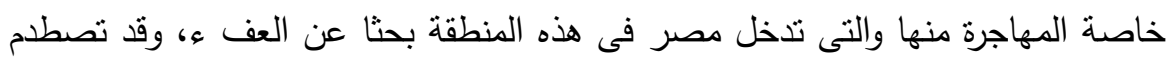

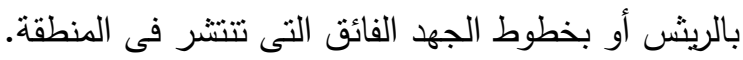

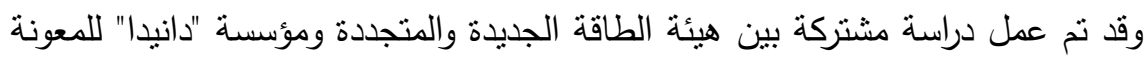

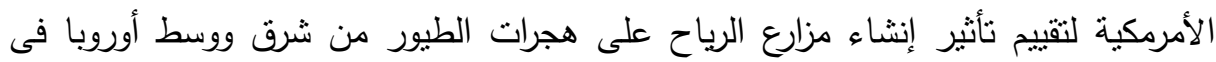

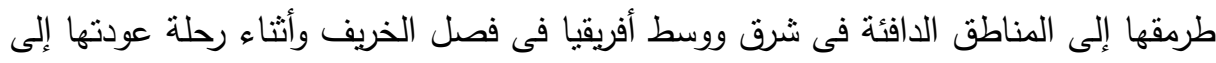
مواطنها الأصلية فى فصل الربيع، وقد تمت هذه الدراسة فى منطقة خليج السويس، حيث تم تم اختيار مساحة قدره 《 ... بكم ץ بمنطقة خليج الزيت على خليج السوس لتحديد معدلات

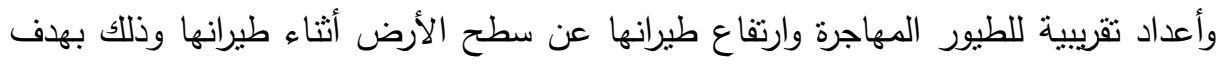

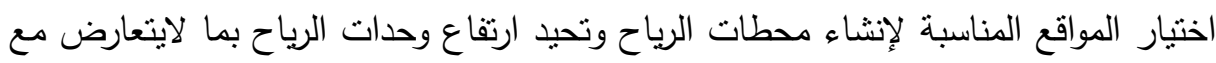

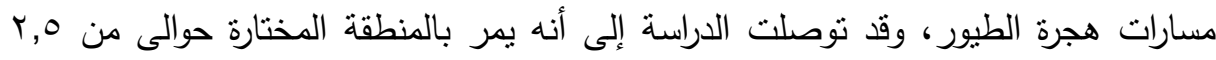

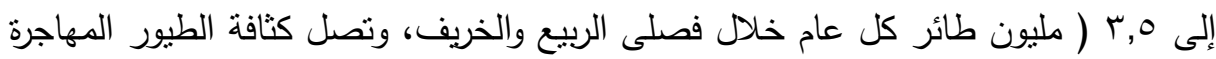

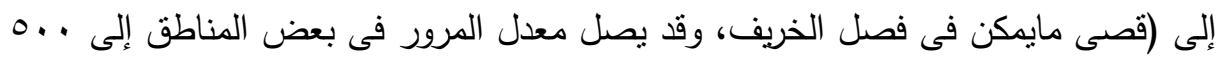
طائر / ساعة عند ارتفاع أقل من . . 1 متر لبعض أنواع الطيور • (هيئة الطاقة الجديدة

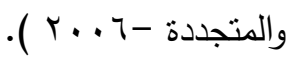

r - الضجيج والتلوث السمعي: ينتج عن تشغيل التربينات الهوائية أصوات غير مرغوب فيها، ويتوقف مقدار ارتفاع الصوت علي نوع التربينة المختارة، وينتج هذا الصوت عن اصطدام

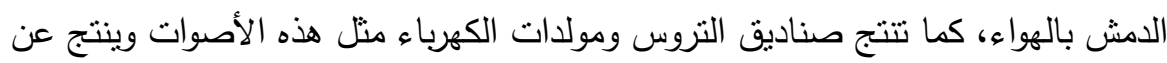
محطات الرياح نوعين من الضجيج أحدهما غير مسموع وتتعكس تأثنراته على الجهاز

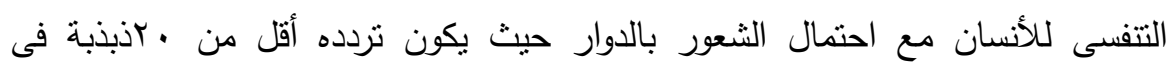

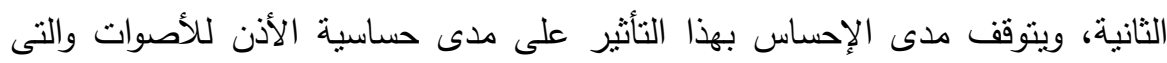

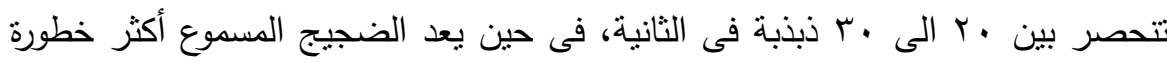

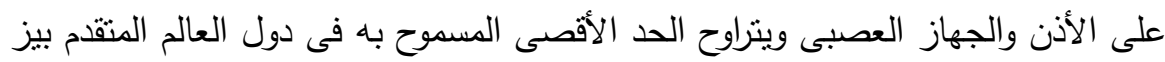


•ـ إلي § ج دى سبيل صوتى، وبذلك يتحدد الحد الأدنى المسموح به للأقتراب من تربينة رياح محددة عند الحد الأقصى لسرعة رياح التشغيل ( إيمان علي المحفوظ -0 . . ب). نظرا لبعد موقع محطة رياح إيطالجين لاينظر تداخل نلك الأصوات فى الأنشطة

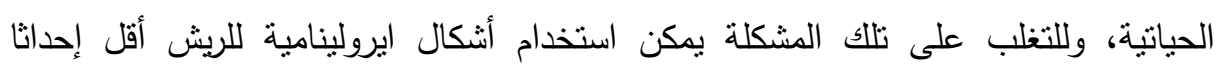
للضوضاء وتقنيل السرعة عند أطراف الريش.(أسامة العادل - بدون ناريخ ).

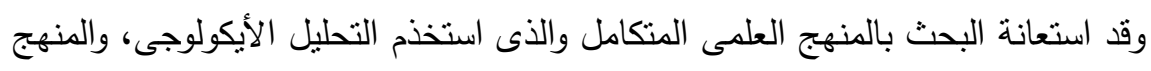
الأنثروبولوجى بأدواتة منل المقابلات الثخصية والأستقصاء (الاستبيان).

\section{قد تضمن البحث مفهومين وهما التقييم البيئى والاجتماعي - التنمية الحضرية:} • تقييم الأثر البيئي والاجتماعي: Assessment Environmental Impact بأنه عملية تقييم الآثار البيئية المُحتملة والمقترحة لمشروع معين، وتحديد الخيارات بهدف تقليل الأضرار البيئية قدر الإمكان، حيث نوفر هذه العملية فرصة لتحديد القضايا المهمة في

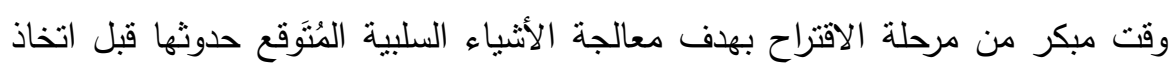
القرارات النهائية.( (au.edu.uow.www) كما عرّفته الرابطة الدولية لتقييم الأثر البيئي (IAIA) على أنه: "هو عملية تحديد،

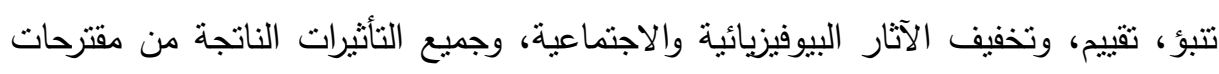

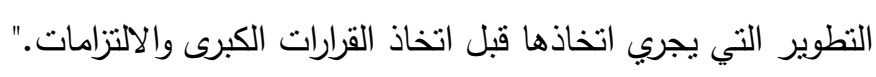

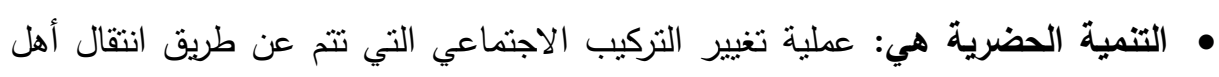

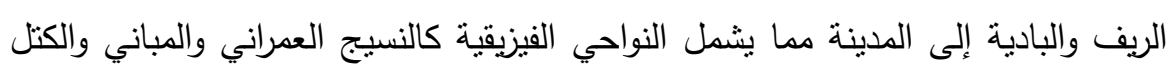

$$
\text { والجوانب الاجتماعية. }
$$

كما أنها عملية نطوير المجتمعات الريفية إلي مجتمعات حضرية كما تثشير كذلك إلي

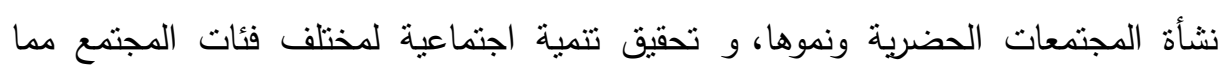
يضمن تحقيق النموالاقتصادي والتوزيع العادل للموارد والمحافظة على البيئة وحمايتها واحترام النتوع التقافي للمجتمع، مما يضمن تلبية متطلبات الأجيال الحالية دون المساومة على تلبية

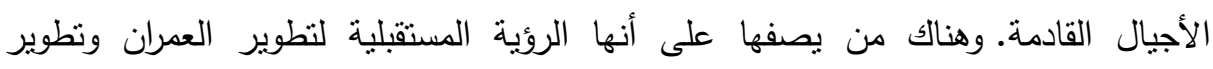
المواصلات ومواجهة التحديات الاقتصادية والسكانية والبيئية التي تحتاج للتتمية المستدامة.

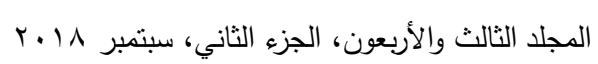




\section{الإجراعائ المنهجية}

البحث من الدرسات الوصفية الذى اعتمد على المنهج العلمى المتكامل والذى استخذم

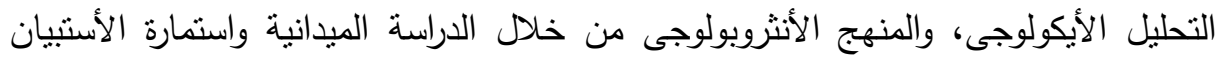
وهو عبارة عن صياغة للجموعة أسئلة معدة سلفاً يقوم السائل بتسجيل إجاباته عليها، عادة الاندان

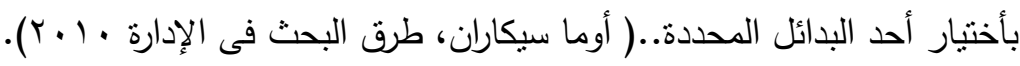

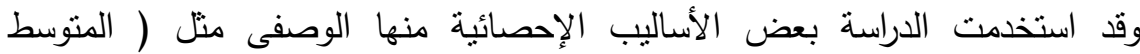

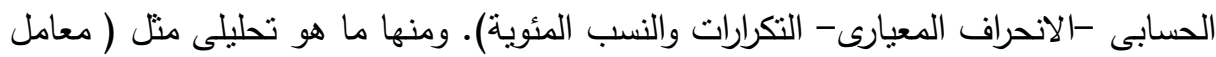
الأرتباط لبيرسون - نموذج الأنحراف المتعدد المتدرج الصاعد - اختبار T- اختبار مربع كآي

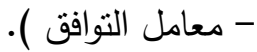

\section{هضوض التراسما}

مجال جغرافى: وادي دارة (مدينة رأس غارب) محافظة البحر الأحمر حيث انها اقرب منطقة بها سكان للمشروع حيث تبعد حوالي بكم وله دنه. مجال بشرى: العاملين بالمزارع - القبائل المقيمة . ويبلغ عدد سكانها حوالي .0نانسمة من المقيميين الدائمين وتشمل قبائل المعايزة والبثايرة والعبابدة. المجال الزمنى: انقسمت فترة العمل الميدانى إلى قسمين الأول قد شمل الدراسة

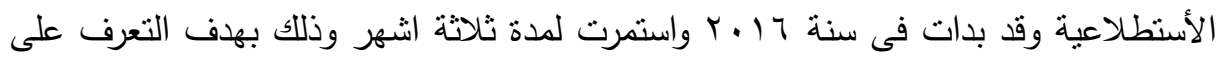

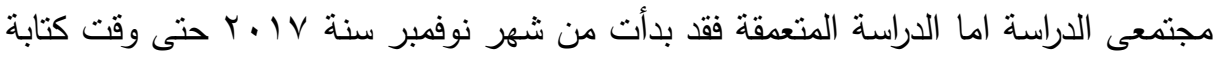

\section{أواليد الهمبه}

• الدراسة الستطلاعية: قبل البدء في الدراسة الميدانية لابد من التطلع على الظروف و الإجراءات التي سيتم فيها إجراء هذا البحث الميداني لهذا جاءت الدراسة الاستطلاعية 
التي مهدت له، والتي اعتبرت مرتكز للبحث الميداني وذلك نظرا لأهميتها في مساعدة الباحث على تطبيق أدوات البحث.

• الملاحظة البسيطة: وقد استخدمت الباحثة الكاميرات الحديثة؛ من أجل الحصول على مشهد واقعي، ويُسهم ذلك في تأصيل الجانب الموضوعي، مع عدم نسيان التفاصيل.

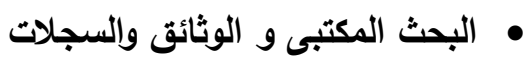
• • الأسلوب الكارتوجرافى لرسم أشكال والخرائط الازمة للبحث.

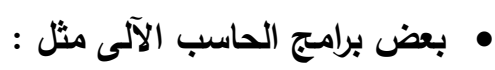

ARC GIS INTERNET PHOTOSHOP -

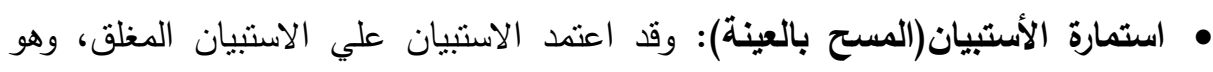

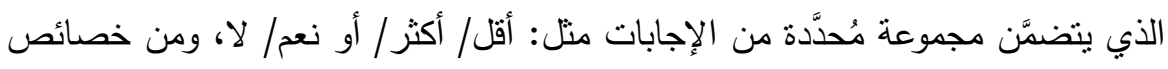
ذللك النوع من الاستبيان سهولة الحصول على الإجابة من قبل المبحوث، وينطلب وفتًا

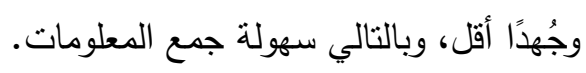

وتم القيام بتجربة الاستبيان على مجموعة من عيّنّة الدِّراسة؛ من أجل التأكُّد من كفاية

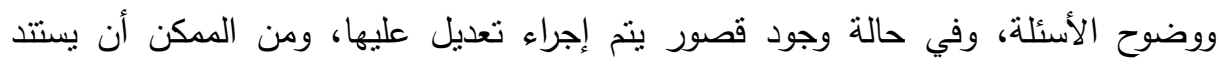

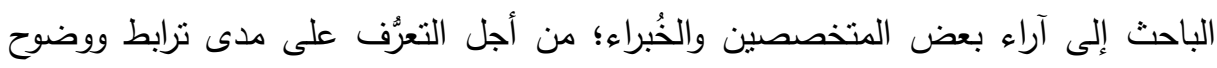
الاستنيان.

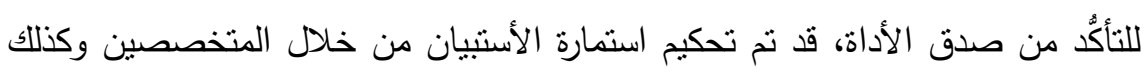

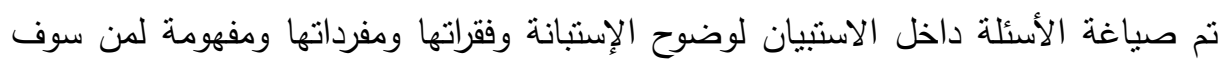

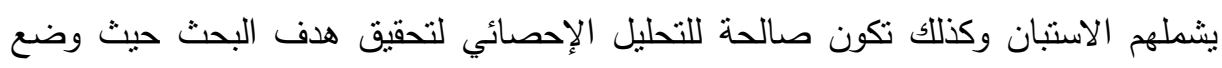

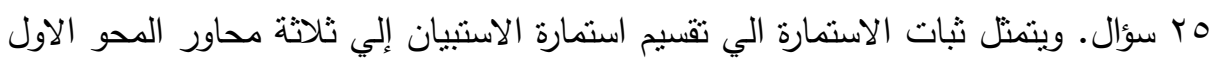

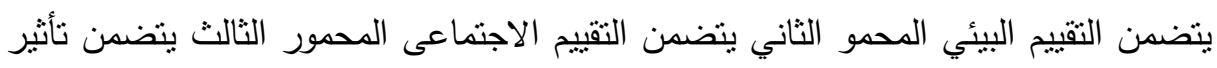
التقييم البيئي والأجتماعى علي التتمية الحضرية، وراعت الباحثة التوازن بين الثناثة محاور. 
وكذللك زيادة عدد خيارات الإجابة مثل أقل/ أكثر/ أو لا / نعم. ولقد تم حساب الثبات علي

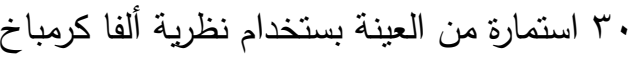

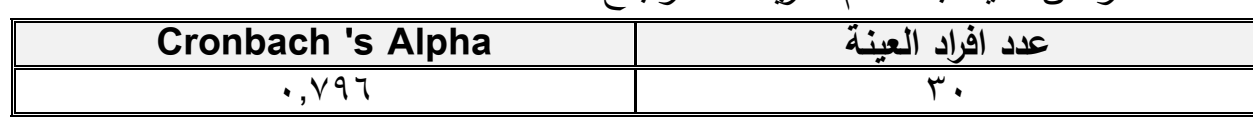

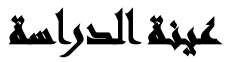

عينة الدراسة مشروع إيطالجين (طاقة رياح): أولا مشروع إيطالجين (قرية وادي دارة ) بمحافظة البحر الاحمر: عينه الدراسة هى ... شخص موزعة الى: الى النين

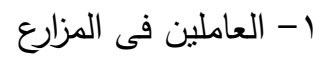

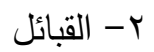

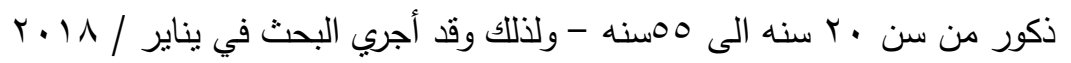

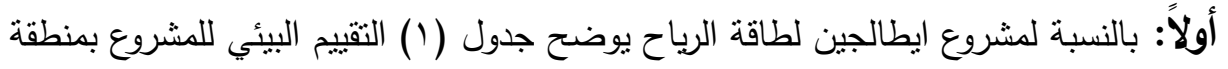

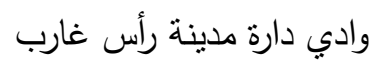

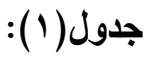

\begin{tabular}{|c|c|c|c|}
\hline غير متأكلا & $\overline{\bar{\nu}}$ & نعع & السؤال \\
\hline$\%$ & $\%$ & $\%$ & التقييم البيئي \\
\hline$\% r$ & $\% 10$ & $\% \wedge r$ & هل سوف يصيب المشروع الطيور الدهاجرة أضرار \\
\hline$\% \varepsilon$ & $\% \mathrm{~V}$ & $\% \wedge 9$ & هل سوف بأثر المشروع على الطيور \\
\hline$\% r$ & $\% \Gamma$ & $\% 90$ & هل هنالك مخاطر من وجود زواحف سامه \\
\hline$\% 1$ & $\% 91$ & $\% 1$ & هل يوجد خطر من وجود حيوانات مفترسه؟ \\
\hline$\% 1$ & $\% 1$ & $\% 9 \wedge$ & هل هلمنقة المحبطة بالمشروع امنةّ؟ \\
\hline
\end{tabular}

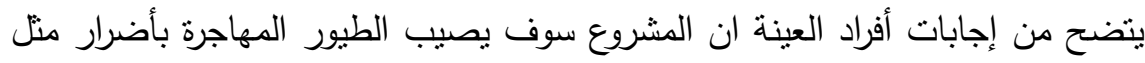

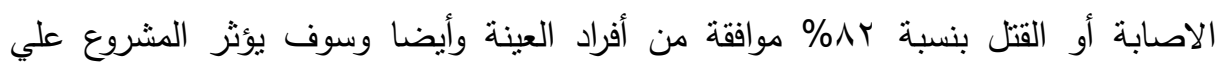

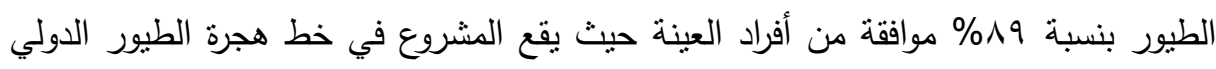

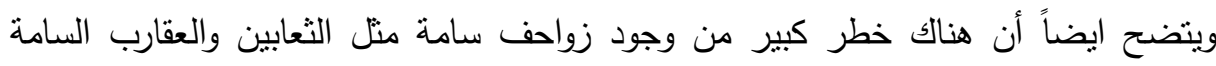
والخطرة بالوادي بنسبة موافقة 9\%\% ولكن ليس هناك من ملاحظة بوجود حيوانات مفترسة بنسبة 
رفض ه^\% بأنه لا يوجد وجود لاي حيوانات مفترسة. ان المنطقة أمنة بنسبة ^9\% موافقة من أفراد العينة. جدول(ץ): يوضح المخاطر الطبيعية بالنسبة لمشروع ايطالجين لطاقة الرياح

\begin{tabular}{|c|c|c|c|}
\hline السيول & الزلازل & الهجوط الارضى & السؤال \\
\hline$\%$ & $\%$ & $\%$ & التقييم البيئح \\
\hline$\% 1 \ldots$ & - & -- & لها المنطقة؛ أكثز المخاطر الطبيعية التي تتعرض \\
\hline
\end{tabular}

يتضح من إجابات أفراد العينة ان أكثر المخاطر الطبيعية التى تتعرض لها المنطقة هي السيول وجاءت نسبة الموافقة . . 1\% من افراد العينة.

جدول(r): يوضح كيفية التخلص من المخلفات في منطقة وادي دارة

\begin{tabular}{|c|c|c|c|}
\hline الصندوق الخاص بها & متعهر & الحرق & السؤال \\
\hline- & - & $\%$ & التقييم البيئي \\
\hline - & - & $\% 1 \ldots$ & في المني طقة؛ التخلص من المخلفات \\
\hline
\end{tabular}

يتضح من إجابات أفراد العينة ان أكثر الطرق للنخلص من المخلفات هي بل وهي

$$
\text { الطريقة الوحيدة هي حرقها بنسبة ... }
$$

ثانياً: بالنسبة لمشروع ايطالجين لطاقة الرياح يوضح جدول (ع) التقييم الاجتماعى للمشروع بمنطقة وادي دارة مدينة رأس غارب

جدول(؟):

\begin{tabular}{|c|c|c|c|}
\hline غير متآكد & $\bar{y}$ & نمعم & 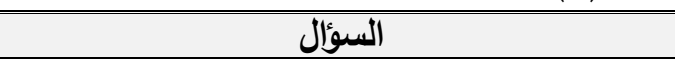 \\
\hline$\overline{-1}$ & $\%$ & $\%$ & التقبيم الاجتماء \\
\hline- & $\% r$ & $\% 9 \wedge$ & هل تعرف مشروع إيطالجين ؟ \\
\hline- & $\% 99$ & $\% 1$ & هل حضرت جلسات الاستماع التي تقوم بها وزاره البيئة؛؟ \\
\hline- & $\%$ r & $\% 91$ & هل مشروع طاقة الرياح (إيطالجين ) مرحب به؟ \\
\hline- & $\% \backslash r$ & $\% \wedge 0$ & هل انت مهتح بمعرفة المزيد عن مشروع إيطالجين؟ \\
\hline- & $\% 99$ & $\% 1$ & هل انت من المشاركين في مشروع إيطالجين \\
\hline$\% 1$ & $\% 11$ & $\% \wedge \wedge$ & -هل انت مهتم بالمحافظة على مشروع إيطالجين؟ \\
\hline$\% 1$ & $\% 1$ & $\% 9 \wedge$ & - هل تحب ان تعدل بالمشروع؟ \\
\hline$\% r$ & $\%$ & $\% 90$ & هل انت راضي عن وجود الششروع بمدينتك؟ \\
\hline$\% 1$. & $\% 70$ & \%ro & هل يمكن ان تطوع بالعمل في المشروع ؟ \\
\hline$\%$ \%. & $\% \vee \varepsilon$ & $\% 17$ & هل هناك دعاية كافية للمشروع قبل بداً تتفيذه؟ \\
\hline
\end{tabular}


يتضح من الجدول السابق ان اكثر افراد العينة يعرفون مشروع إيطالجين بنسبة موافقة

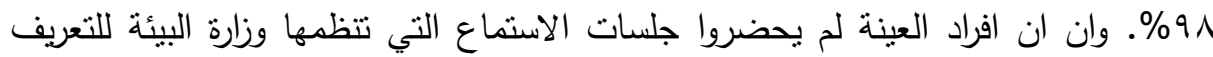
بالمشروع بنسبة 91\% لم يحضرون ولم يتم دعوتهم للحضور ولا توجد اعلانات مسبقة لحضور هذه الجلسات.

أما عن نسبة الترحيب بالمشروع من افراد العينة بنسبة ه^\% موافقة لانها سوف تزيد

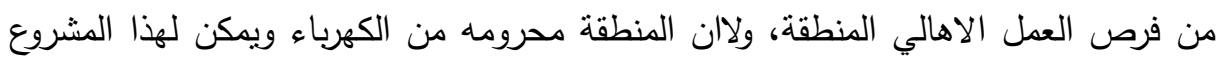
ان يزيد من فرص انارة المنطقة.

أن المشروع إيطالجين مرحب به بشكل كبير من قبل افراد العينة وهذا مؤشر عن نسبة

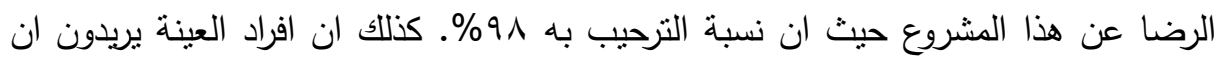
يعرفون معلومات أكثر عن المشروع بنسبة 01\% ومتي يبدأ العمل به. أما عن المشاركة

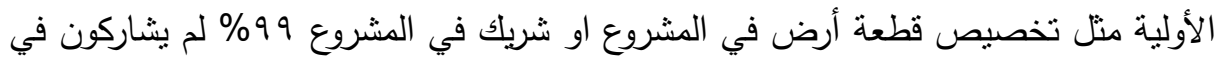

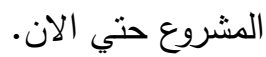

أما المحافظة علي المشروع فقد أبدي أفراد العينة أستعداد كبير للمحافظة علية وحماية

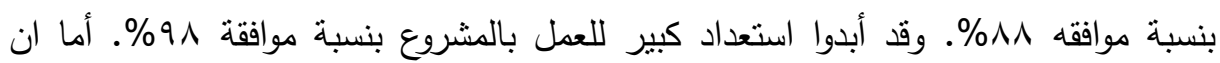
ينطوع الافراد في العمل بالمشروع بأجر بسيط او بدون اجر جاءت النسبة بالموافقه ضعيفة

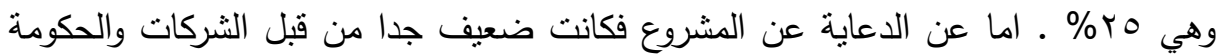

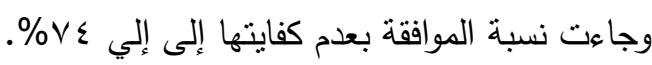

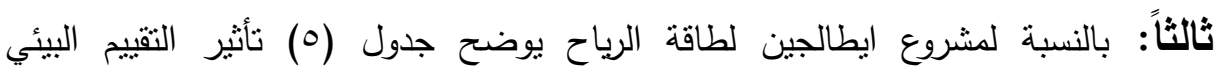
والاجتماعى على التتمية الحضري بمنطقة وادي دارة مدينة رأس غارب لئب

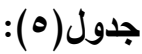

\begin{tabular}{|c|c|c|c|}
\hline غير متأكد & $\bar{y}$ & نعبم & السؤال \\
\hline$\overline{\%}$ & $\%$ & $\%$ & نآثير التقييم البيئي والاجتماعى على التتمية الحضري \\
\hline$\% 1$ & $\% 9 \wedge$ & $\% 1$ & - هل الخدمات الموجودة بالمدينة كافية لأقامة مشروعات \\
\hline- & $\% 99$ & $\% 1$ & - هل الكهرباء كافية في هذه المنطقة لحاجة السكان؟ \\
\hline- & $\% 1 \ldots$ & & هل يوجد وحدة آسعاف؟ \\
\hline
\end{tabular}


أمبرة أحمد عبد الظاهر وآخرون

\begin{tabular}{|c|c|c|c|}
\hline- & $\%$ & & هل يوجد مسنتشفي بالمنطقة؟ \\
\hline$\% 1$ & $\% \varepsilon$ & $\% 90$ & هل الطريق من المدينة للمشروع أمن؟ \\
\hline$\% 1$. & \%ro & $\% 70$ & هل يمكن نقل إحتياجات المشروع من مواد للبناء ومعدات \\
\hline$\% r$ & $\% 1$. & $\% \wedge \wedge$ & 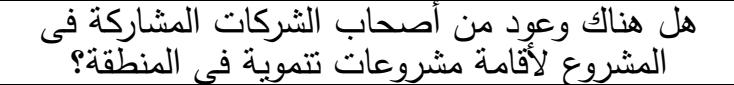 \\
\hline
\end{tabular}

وجد من الجدول السابق ان الخدمات الموجودة بمنطقة وادي دارة سواء سواء خدمات صحية

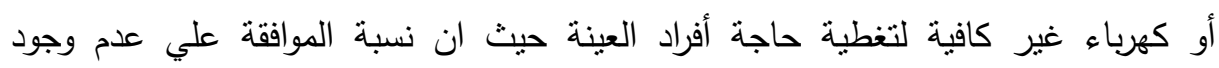

$$
\text { مسنتفي او عربة اسعاف ... 1). }
$$

أما عن خدمات الطريق فهو امن حيث يقوم القبائل بالتأمين له وذللك بنسبة موافقة

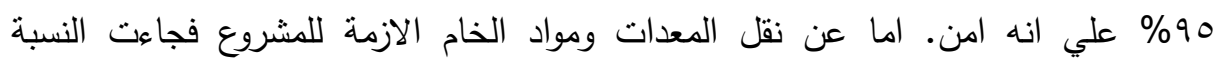
بالموافقه

أما عن وعود اصحاب الشركات نسبة الموافقة علي وجود وعود مثل توصيل الكهرباء كانت \%^^\% من أفراد العينة. رابعاً:

جدول(†): يوضح معامل ارتباط بيرسون بين التقييم البيئي والأجتماعى والتمية الحضرية

\begin{tabular}{|c|c|c|c|}
\hline التتمية الحضرية & والآجتيماعي البئى & & المتغيرات المستقلة \\
\hline $.238(*)$ & 1 & معامل ارتباط بيرسون & \multirow{3}{*}{ والاجنماعى والجنغرافي } \\
\hline .018 & & الدلالة المعنوية & \\
\hline 100 & 100 & 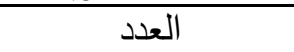 & \\
\hline 1 & $.238(\%)$ & معامل ارتباط بيرسون & \multirow{3}{*}{ التتمية الحضرية } \\
\hline & .018 & الدلالة المعنوية & \\
\hline $1 \ldots$ & $1 \cdots$ & العدد & \\
\hline
\end{tabular}

من مصفوفة معاملات الارتباط نجد انه نوجد علاقة ارتباط قوى بين كل متغيرين عند مستوى

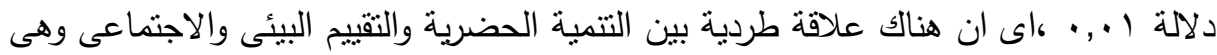

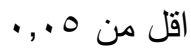




\section{تهمسير المنتائية}

$$
\text { توصلت الدراسة إلي الآتي : }
$$

• إن المشروع يقع في خط هجرة الطيور الدولي وسوف يأثر على الطيور حيث انها قد تتعرض للاصابه نتيجة اصتدامها بالتربينات اثثاء التشغيل.

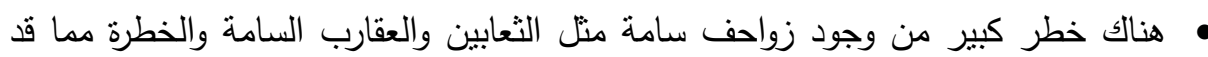

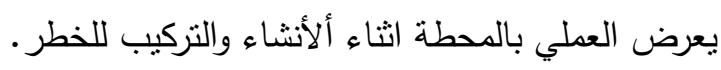

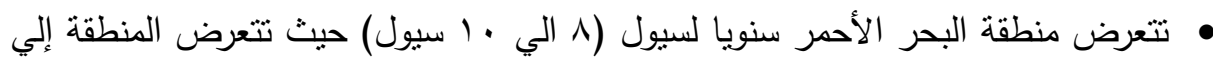
ثلاثة منخفضات هما منخفض البحر الأحمر - التيار النفاث - الظروف الجويه المحلية ) (Abd Alla,- 2003,P.58-59) المناسب اثثاء مرحلة الانثاء.

• ل ال يوجد طريقة امنه بيئياً في منطقة وادي دارة للتخلص من المخلفات الصلبة والعضوية مما بتطلب من المشروع إيضاح لكيفية التخلص من هذه المخلفات بطريقة بيئية وحضريه. • انه لا يوجد دعاية منظمة وهادفة تهدف لتعريف المجتمع بالمشروع حيث تقوم وزارة البيئة بتتظيم جلسات استماع فقط في المدن الحضرية القريبة من المشروع وتغفل القري

$$
\text { والمناطق الأقرب للمشروع من المدينة. }
$$
• لا توجد خطة واضحة للمشاركة المجتمعية في المشروع كتحديد نسبة المشاركين ( سواء الأهن بالعمل بإجر او من المتطوعين او نسبة المشاركه للجمعيات الاهلية بالمشروع ) من ابناء

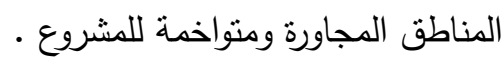
• نلاحظ افتقار منطقة الدراسة لخدمات البنية التحتية وخاصتاً الكهرباء حيث تعتىد المنطقة علي المولدات الكهرابيئية التي تعمل بالمواد النفطية. • عدم توافر للخدمات الصحية من وحدات صحية ومستشفيات في منطقة الدراسة، فاقرب مستشفي مجهز في رأس غارب وهي مسنتفي رأس غارب العام وتبعد عن منطقة الدراسه والمشروع بحوالي ه مكم. 


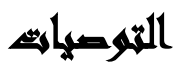

• وضع خطه نتموية واضحه قبل البدء في مشروعات الطاقة المتجددة الكبري، للمناطق

التى تفقتر إلي الخدمات الأساسية لمد خطوط التتمية إليها.

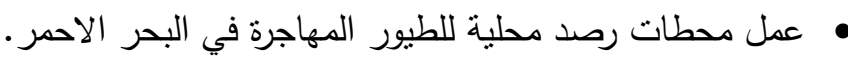

إنشاء بنك للمعلومات عن سرعة الرياح واتجاهها وباقي كافة البيانات المناخية والطقسية الطية

المؤثرة والتي يحتاجها المستتمر .

•عمل جهه حكومية خاصة بالتقييم البيئي والاجتماعي للمشروعات المختلفه.

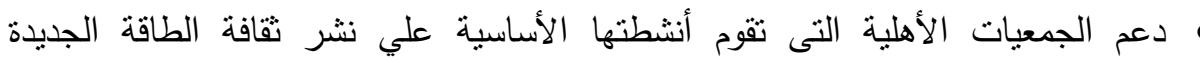

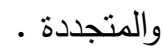

• رفع الجمارك علي معدات الطاقة النظيفة.

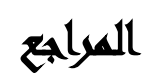

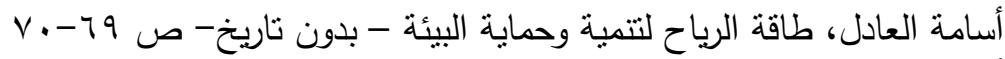

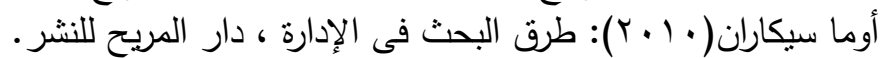

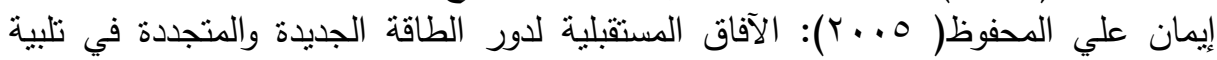

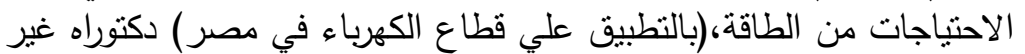

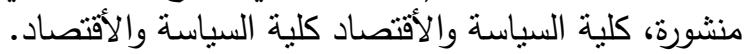

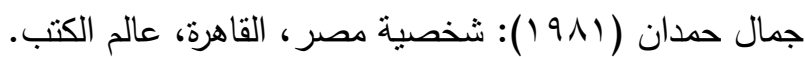
دراسة مستقبل الطاقة الثمسية في مصر الجهاز المركزي للتعبئة العامة والاحصاء - التقرير

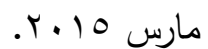

رئاسة الجمهورية - المجاس القومية المتخصصة - طاقة الرياح بمصر - التقرير الثانى -

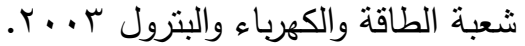

محمد على أحمد - الطاقة النظيفة الصديقة للبيئة - كلية العلوم - جامعة القاهرة - دار

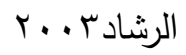

محمد محمود إبراهيم الديب( •99 (1): الطاقة فى مصر ، مكتبة الانجلو المصرية

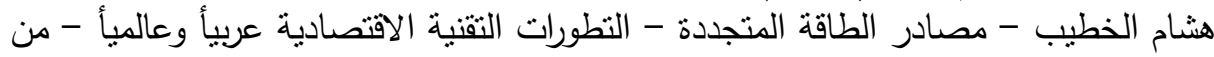

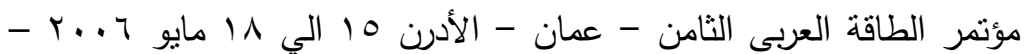

ص صن 119619

هيئة الطاقة الجديدة والمتجدة، التقرير السنوي • ( • r، صفحات متفرقة، بيانات منشوره.

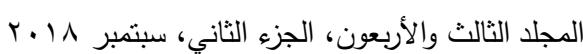




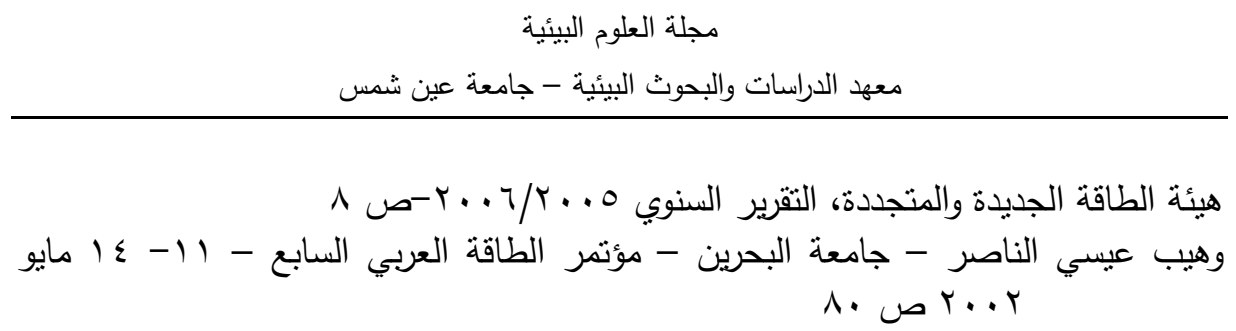

Azmel,H-Renewable Energy,Globalpers pectives ,Icfai University press ,2010,p6.

Oppenheim, A. (1992): Questionnaire Design, Interviewing and Attitude Measurement, London, Pinter.

Steve Sawyer, Arthouros Zervos- Gwec-Global Wind 2007

Report - Second Edition May 2008 P62-63-1/2/2013

Utility Scale Solar Power Plants, A Guide for Developers and Investors,International Finance Corporation group, World Bank 2012.

https://www.un.org/sustainabledevelopment/ar/2016/02/أمام-القمة-العالمية-امبية لطاقة_المستقبل

http://www.eeaa.gov.eg/ar-eg

www.eeaa.gov.eg/portals/0/eeaaReports/NCC/

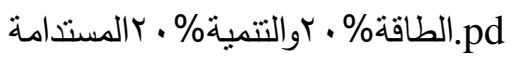

www.uow.edu.au, Retrieved 14-1-2018. Edited 
أميرة أحمد عبد الظاهر وآخرون

\title{
ENVIRONMENTAL AND SOCIAL ASSESSMENT OF THE WIND TURBINE PROJECT IN WADI DARRA - RAS GHARIB AND ITS IMPACT ON URBAN DEVELOPMENT
}

\author{
Abdel Zaher, Amira, A. ${ }^{(1)}$; El - Sarsi, M. A. M. ${ }^{(2)}$ \\ and Hussein, M. A. ${ }^{(3)}$ \\ 1) Institute of Environmental Studies \& Research, Ain Shams \\ University 2) Faculty of Women, Ain Shams University 3) Faculty of \\ Arts, Damietta University
}

\begin{abstract}
The main objective of this study was to present the requirements of the environmental and social assessment of the wind energy project and the impact of this assessment on urban development in Wadi Dara village in Ras Gharib city. As well as the social satisfaction of the study community on the project, as well as the most important environmental and geographical (natural and human) factors affecting the establishment of this project. In order to achieve these objectives, this study was conducted in the above mentioned area as a geographical area. The field study was based on the questionnaire. The study was chosen as a simple random sample of the population of this area. The questionnaire included a questionnaire of 100 people. Social development, urban development, and environmental and social impacts on urban development. The study used some descriptive statistical methods such as (mean- standard deviation - frequencies and percentages). Some of these are analytical (Pearson's correlation coefficient - the progressive gradient deviation model). The initial test period for the questionnaire form and field data collection took about three months.
\end{abstract}

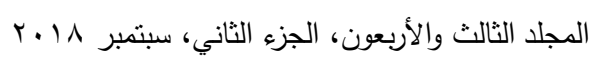


مجلة العلوم البيئية

معهد الدراسات والبحوث البيئية - جامعة عين شمس

The study concluded with the most important results and the results of these scientific recommendations are applicable to achieve a breakthrough in environmental and social assessment in order to plan for better urban development 